\title{
UC ANR Cooperative Extension grows citizen scientists
}

\author{
ast year, as part of the May 8 centennial of the \\ founding of the Cooperative Extension Service in \\ the United States, UC ANR Cooperative Extension \\ (UCCE) invited Californians to take a walk or visit a park \\ or garden and be citizen scientists. The goals were to \\ crowd-source information on pollinators, water use, \\ and food production and consumption and to give \\ participants a shared experience of observing and \\ reporting on the world around them.
}

Each UCCE county office held centennial events. The Humboldt and Santa Cruz county offices provided public farm tours; in Del Norte County, UCCE staff visited school classrooms; in Fresno, Monterey and San Diego counties, staff hosted the public at their offices; Ventura County invited the public to a UC research and extension center; and other counties participated in commu-

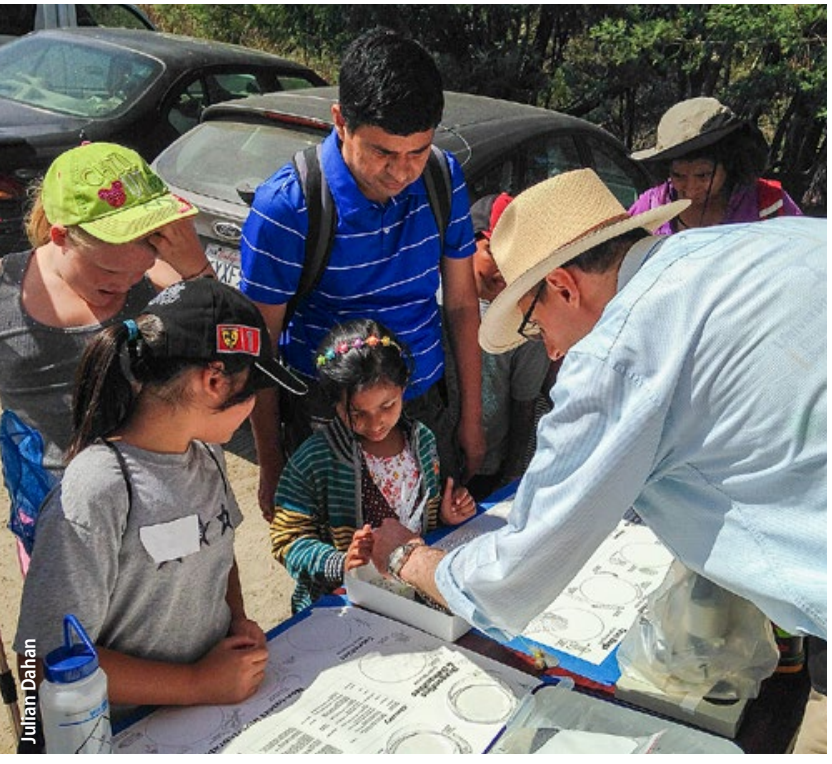

UCCE advisor lgor Lacan shows kids how to identify the insect species in their stream samples. nity events, such as the one held at the California Academy of Sciences in San Francisco.

Both the date and the design of the project were significant. One hundred years earlier, on May 8, 1914, President Woodrow Wilson signed the Smith-Lever Act, creating the United States Agricultural Extension Service - which became, in California, UCCE. Since then, the federalstate-county partnership that UCCE represents has consistently promoted citizen science and service by enabling communities to pose research questions about agricultural, natural and human resources and to work in partnership with university researchers to find answers.

Last year's May 8 activities were also intended to connect modern-day Californians with a tradition of citizen science in the United States that began well before the Smith-Lever Act became law. For most of our nation's history, access to higher education was a privilege reserved mostly for the wealthy. But a lack of formal educational opportunities didn't rule out the possibility of scientific observation and experimentation in agriculture and other areas. American farmers were active citizen scientists, observing, experimenting and sharing information with other farmers in agricultural societies and at agricultural fairs and expositions. By the end of the 19th century, more than 3,000 agricultural publications had appeared in the United States and Canada. This culture of land-based learning and inquiry helped to foster a trajectory of federal legislation - beginning with the Morrill Land Grant Act signed into law by Abraham Lincoln in 1862 - that affirmed the importance of science-based inquiry and the vital contributions of governmentfunded scientific research to the public good.

\section{Gathering data on May 8, 2015}

Participants were invited to respond to one, two or all three surveys:

- How are you conserving water in your home, garden, yard or farm?

- Where is food grown in your community, and how do you get most of your food?

- How many pollinators can you count in 3 minutes?

Participants submitted their responses with a computer or smartphone. Responses were automatically tagged with location data, which enabled UCCE to map the location where each response was submitted and categorize it as urban or rural, based on the geographic classifications used by the U.S. Census Bureau. Between $62 \%$ and $69 \%$ of the responses were submitted from urban areas, depending on the survey. Every county in the state was represented among the respondents.

\section{Water conservation}

UCCE received responses to this question from more than 8,300 people. The large majority of respondents from rural and urban areas reported adopting basic water conservation practices, such as taking shorter showers (73\% rural, $75 \%$ urban) and reducing landscaping water (71\% rural, 79\% urban). A smaller proportion reported more aggressive measures to reduce water use, such as undertaking some form of gray water reuse (22\% rural, $15 \%$ urban) and capturing and reusing rainwater runoff (15\% rural, $11 \%$ urban). Of the respondents who reported running a 
farm, roughly half said they were using drip irrigation.

California is in the midst of a long drought, and messages about water conservation appear to be reaching the public. UCCE is uniquely poised to help farmers, urban and rural residents and agencies work through the conservation challenges that this historic drought demands (see ciwr.ucanr.edu/).

\section{Food}

Just under 10,000 people submitted responses for this survey.

Interestingly, responses to the question, "Where do you get most of your food?" were closely aligned across rural and urban respondents: $86 \%$ of rural respondents versus $85 \%$ of urban respondents answered "from a grocery store," 38\% rural versus 38\% urban said "from a farmers market," $11 \%$ rural versus $10 \%$ urban said from a community supported agriculture (CSA) farm, and 37\% rural versus $38 \%$ urban said "from a garden or farmer directly" (percentages total more than 100 because respondents were allowed to choose more than one food source).

Another series of questions asked respondents to use an online map to identify the location of a garden or farm and provide some information about it (see photo). Of the foodproduction locations submitted from rural locations, $40 \%$ were home gardens, $18 \%$ were community or school gardens and $42 \%$ were farms. Of the food-production sites submitted from urban areas, $57 \%$ were home gardens, $31 \%$ were school or community gardens and $11 \%$ were farms.

\section{Pollinators}

UCCE received responses to this survey from more than 10,600 people. Respondents showed great interest in counting bees, birds, bats and flies, which help distribute pollen that is essential to the production of many of the foods we eat. Public interest in pollinators has surged since the emergence of honeybee colony collapse disorder in 2007.

On May 8, 2014, kids and adults counted and recorded 17,861 bees, 7,582 flies, 7,548 birds, 2,518 butterflies, 2,345 beetles, 1,459 wasps, 1,021 moths and 173 bats. Urban and rural respondents submitted similar counts. There were differences between age groups: 18- to 29-yearolds saw the most bees, at 14 per respondent (an individual or a group of individuals), whereas 30- to 59-year-olds saw the most birds, at 4 or 5 per respondent. The ability to record and recognize pollinators

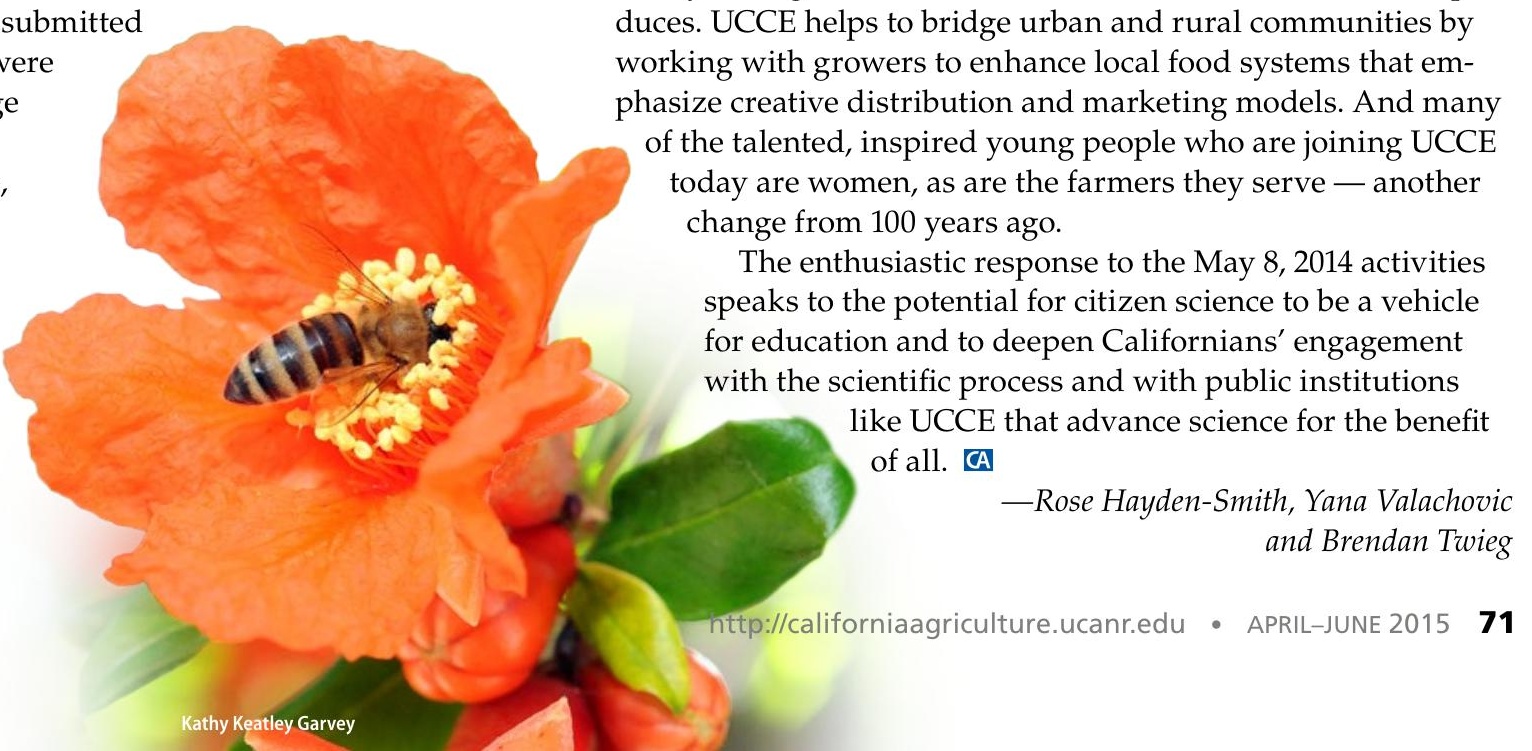
duces. UCCE helps to bridge urban and rural communities by working with growers to enhance local food systems that emphasize creative distribution and marketing models. And many of the talented, inspired young people who are joining UCCE oday are women, as are the farmers they serve - another hange from 100 years ago.

The enthusiastic response to the May 8, 2014 activities speaks to the potential for citizen science to be a vehicle for education and to deepen Californians' engagement -Rose Hayden-Smith, Yana Valachovic and Brendan Twieg

\section{Conclusion}

When Cooperative Extension was created in 1914, the nation was at the beginning of a rural-urban population shift. Cooperative Extension primarily served rural residents to help improve on-farm productivity, to enhance home life through teaching best practices in home management and economics (including activities such as food preservation and poultry keeping), and to provide youth development programs in these areas.

While many of these themes persist, Cooperative Extension has evolved to reflect present-day sensibilities and needs. Cooperative Extension still partners with farmers to improve on-farm productivity, though it now also serves the increasing number of farmers and gardeners in cities and suburbs. Cooperative Extension continues to support small animal husbandry, but a growing number of clientele are based in urban areas. UCCE's Master Food Preserver food program is having difficulty meeting the surging demand for courses in urban areas, where residents - many of them generations removed from the farm - are seeking to acquire skills to improve their ability to be good stewards of the abundant food California pro- 